\title{
Dislocation of a sutureless prosthesis after type I bicuspid aortic valve replacement
}

\author{
Giovanni Alfonso Chiariello, $\mathrm{MD},{ }^{\mathrm{a}, \mathrm{b}}$ Emmanuel Villa, $\mathrm{MD}, \mathrm{PhD},{ }^{\mathrm{a}}$ Antonio Messina, $\mathrm{MD}, \mathrm{PhD},{ }^{\mathrm{a}}$ and
}

Giovanni Troise, MD, ${ }^{a}$ Brescia and Rome, Italy

\footnotetext{
From the a Cardiac Surgery Unit, Poliambulanza Foundation Hospital, Brescia, Italy; and ${ }^{\mathrm{b}}$ Cardiovascular Sciences Department, Catholic University of The Sacred Heart, Rome, Italy.

Disclosures: G.T. is proctor for LivaNova. All other authors have nothing to disclose with regard to commercial support.

Received for publication Nov 23, 2017; revisions received Jan 11, 2018; accepted for publication Feb 4, 2018; available ahead of print March 8, 2018.

Address for reprints: Giovanni Alfonso Chiariello, MD, Cardiovascular Sciences Department, Catholic University of The Sacred Heart, Largo A. Gemelli 8, 00168 Rome, Italy (E-mail: gio.chiariello88@ tiscali.it).

J Thorac Cardiovasc Surg 2018;156:e87-9

$0022-5223 / \$ 36.00$

Copyright (C) 2018 by The American Association for Thoracic Surgery

https://doi.org/10.1016/j.jtcvs.2018.02.002
}

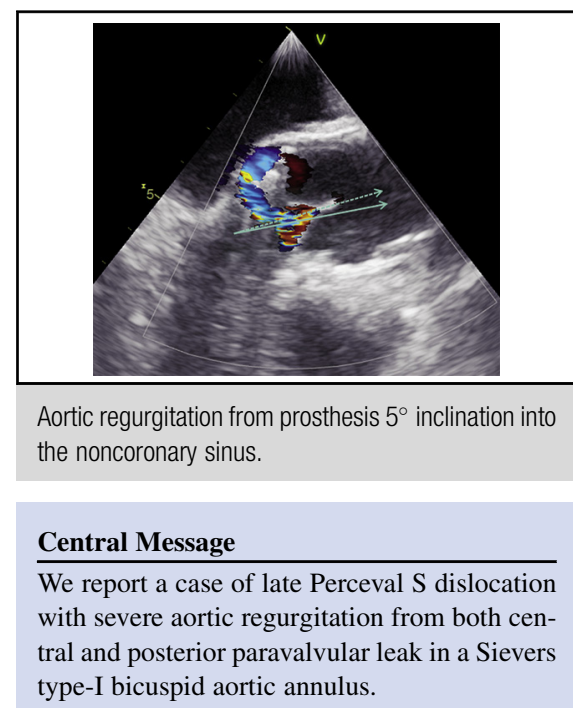

See Editorial Commentary page e91.
Perceval S (LivaNova PLC, London, United Kingdom) sutureless valve implantation is a valid surgical technique for reinterventions and minimally invasive procedures. ${ }^{1}$ Indications for Perceval $\mathrm{S}$ implantation in patients with type 1 bicuspid aortic valve (BAV-I) replacement remain controversial, with manufacturer instructions contraindicated its use in such cases. In contrast, a recent 1-year follow-up of 25 patients with Perceval S implantation for BAV-I yielded an overall survival of $88 \%$ without severe paravalvular leaks, valve displacement, or structural deterioration. ${ }^{2} \mathrm{We}$ report a case in which a central intraprosthetic leak after bailout replacement of a BAV-I was apparently caused by inadequate leaflets coaptation because of the displacement of the valve.

\section{CASE REPORT}

A 67-year-old woman who was obese, had hypertension, and had symptoms of dyspnea (New York Heart Association functional class III) was admitted to our cardiac surgery unit for aortic valve replacement with an echocardiographically diagnosed severe calcific tricuspid aortic valve stenosis (area of $0.8 \mathrm{~cm}^{2}$, peak pressure gradient of $73 \mathrm{~mm} \mathrm{Hg}$, mean of $45 \mathrm{~mm} \mathrm{Hg}$, and left ventricular ejection fraction of $67 \%$ ). Intraoperative transesophageal echocardiography confirmed the diagnosis. Through a "reversed-T" upper ministernotomy, a transverse aortic incision more than $3.5 \mathrm{~cm}$ from the aortic annulus was performed. The aortic root was normal in terms of diameters, and the 3 Valsalva
Video clip is available online.

sinuses appeared symmetric. At surgical inspection, the aortic valve unexpectedly appeared to be bicuspid type I R-L according to the Sievers classification. The valve was excised, and the annulus was accurately decalcified and débrided to obtain a regular circumference. Because of the height of the aortotomy, the precarious exposure through the minimally invasive approach in an obese patient, the preserved sinotubular junction, and the recent encouraging results reported for the Perceval valve implanted in type I bicuspid annuli, ${ }^{2}$ a Perceval S sutureless valve was chosen as bailout procedure. Three 4-0 Prolene (Ethicon Inc, Somerville, NJ) guiding sutures were positioned starting $2 \mathrm{~mm}$ below the annulus and reciprocally distanced of $120^{\circ}$, with the aid of a tripartite aortic annulus sizer for correct positioning of the 3 recreated nadirs. ${ }^{2}$

A size XL Perceval S valve was implanted, and the sutures were removed. Intraoperative and postoperative echocardiograms confirmed the correct positioning and function of the bioprosthesis (peak gradient of $8 \mathrm{~mm} \mathrm{Hg}$ ); in particular, the absence of paravalvular leaks was documented (Figure 1, A). Postoperative course was uneventful, and the patient was discharged on postoperative day 6. During the first year of follow-up, the patient was free of symptoms and in good clinical condition. Postoperative echocardiography showed the Perceval S prosthesis to be normally positioned, with an absence of aortic regurgitation. Fourteen 


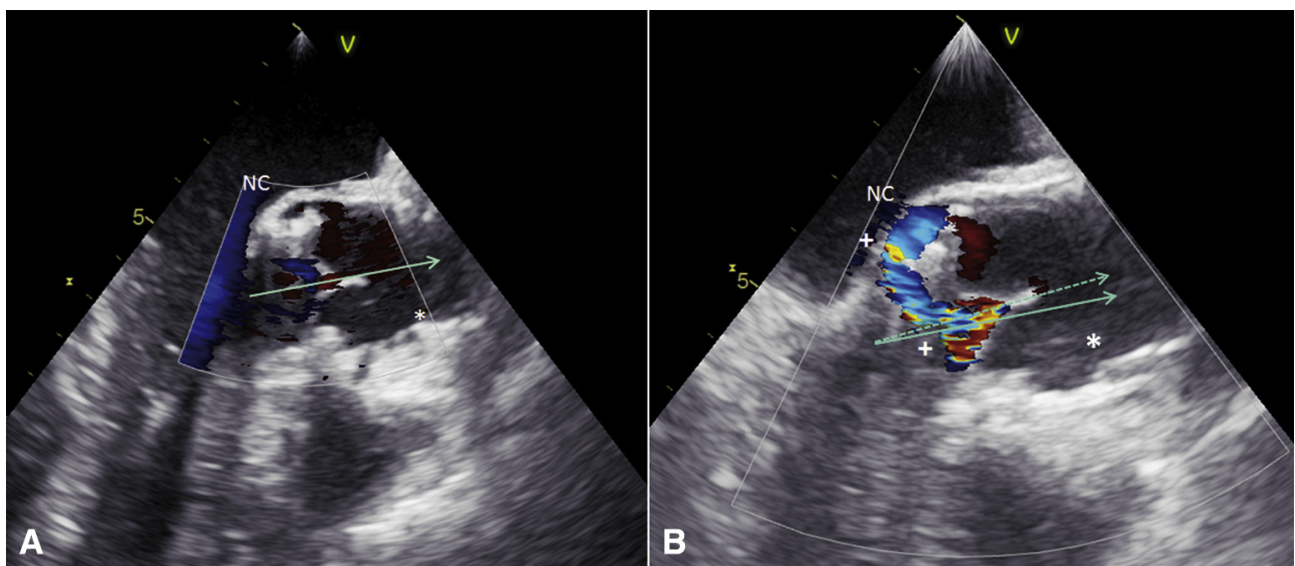

FIGURE 1. Intraoperative transesophageal echocardiograms. A, Perceval S early after the first implantation appears to be normally functioning and correctly positioned, with an appropriate orientation relative to the ascending aorta long axis (solid arrows). B, Perceval S 22 months later appears to have migrated, with upstream and posterior displacement (dashed arrow) of about $5^{\circ}$ into the noncoronary sinus, showing a central as well as a posterior paravalvular leak (plus signs). Asterisk indicates Perceval nitinol stent border. NC, Noncoronary sinus.

months later, the patient underwent a new echocardiogram, which showed moderate aortic regurgitation with suspicion of possible prosthetic dysfunction. Twenty-two months later, the patient became dyspneic again. The readmission echocardiogram revealed severe aortic regurgitation from both central and posterior paravalvular leaks, at the level of the noncoronary sinus. The prosthesis appeared to be dislocated, with upstream and posterior displacement of about $5^{\circ}$ into the noncoronary sinus (Figure $1, B$ ).

At reoperation, the chest was reentered through a full sternotomy, and a transverse aortotomy was performed. The bioprosthesis appeared to be displaced as anticipated
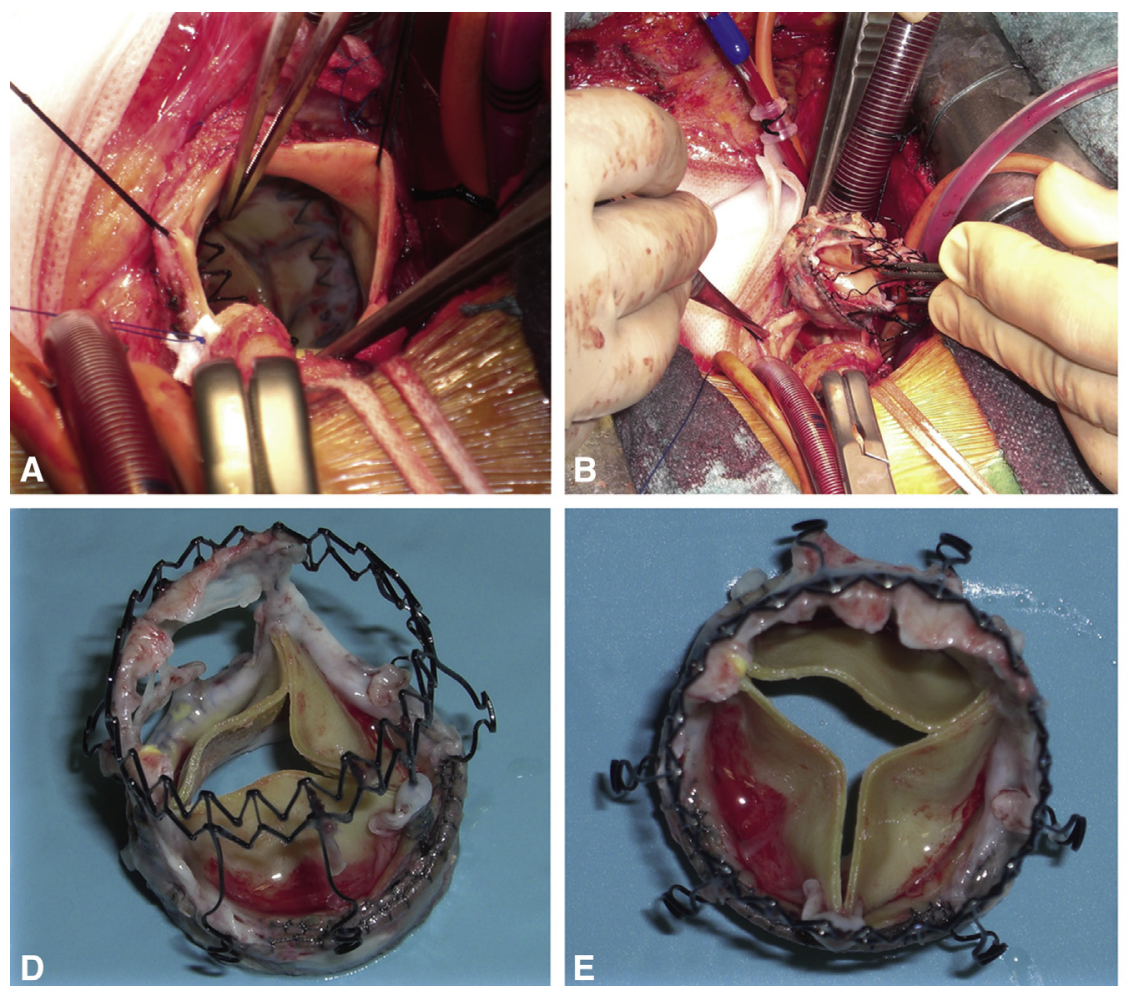
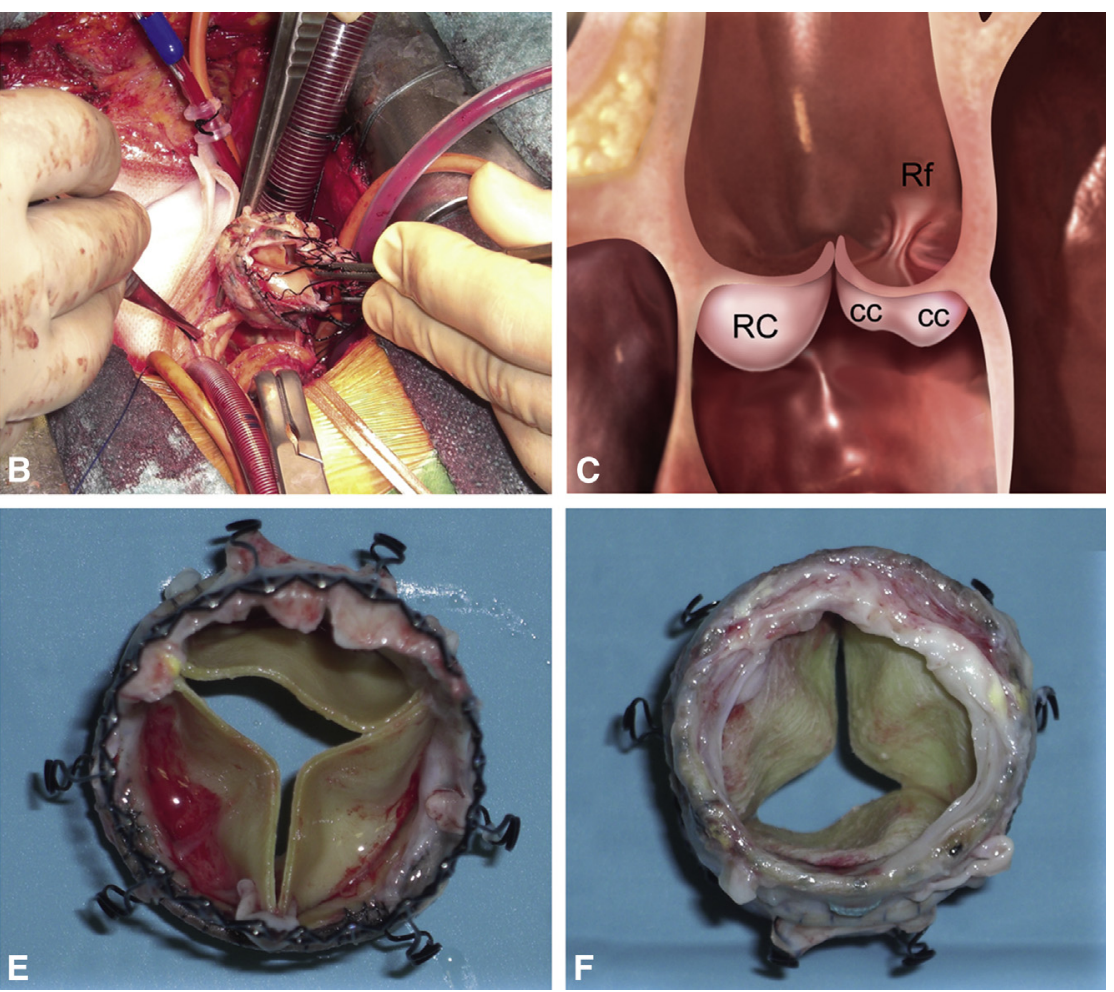

FIGURE 2. A and B, Photographs of dislocated Perceval prosthesis (A) and subsequent removal (B). C, Illustration of a bicuspid valve enhancing the different depth between the reference cusp $(R C)$ and the conjoint cusp $(C C)$. D-F, Explanted Perceval S extensively covered by the neoendothelial tissue. No sign of structural deterioration was evident. $R f$, Raphe. 


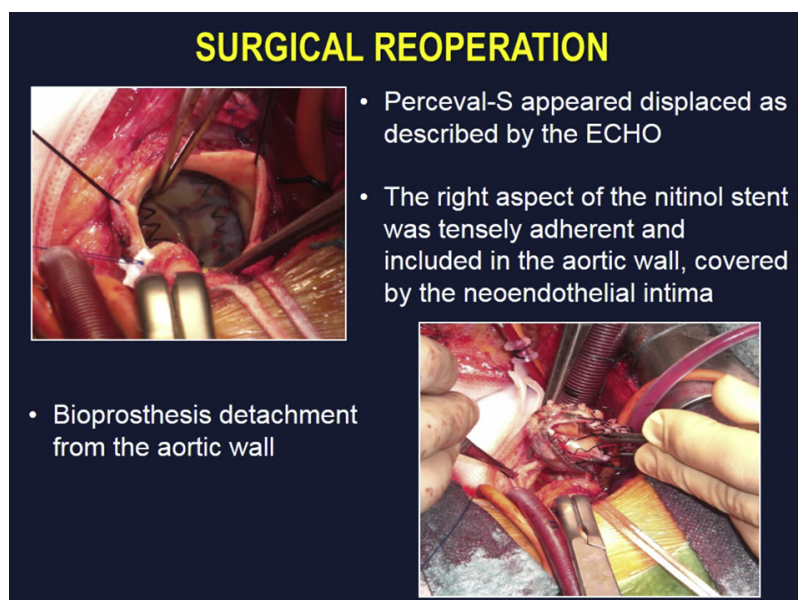

VIDEO 1. Narration of the clinical case and brief discussion, with pictures and echocardiographic clips. NYHA, New York Heart Association functional class; $L V E F$, left ventricular ejection fraction; $A V R$, aortic valve replacement; $C P B$, cardiopulmonary bypass; $I F U$, instructions for use; $R f$, raphe; $R C$, reference cusp; $C C$, conjoined cusp; $B A V-I$, type 1 bicuspid aortic valve. Video available at: http://www.jtcvsonline.org/article/S00225223(18)30336-2/fulltext.

from the echocardiography. The right aspect of the nitinol stent was tensely adherent and included in the aortic wall, extensively covered by the neoendothelial intima (Figure 2, A). Bioprosthesis detachment from the aortic wall was delicate and time-consuming. At the completion of its removal (Figure 2, B), the prosthetic valve showed neither structural degeneration nor signs of thrombosis or infection (Figure 2, D-F, and Video 1).

A 23-mm stented tissue valve was implanted in the supraannular position. Cardiopulmonary bypass time was $121 \mathrm{mi}-$ nutes, and crossclamp time was 85 minutes. Postoperative course was uneventful.

The institutional review board approved the reporting of this case.

\section{DISCUSSION}

Perceval S valve sutureless implantation has proven to be a valid surgical technique, especially suitable for patients at intermediate to high risk, for reinterventions, and in cases of more difficult access, such as minimally invasive procedures. ${ }^{1}$ Indications for Perceval $\mathrm{S}$ implantation in patients with type I bicuspid aortic valve (BAV-I) replacement remain controversial. According to the manufacturer's instructions for use, the Perceval $\mathrm{S}$ is contraindicated in these cases. Nguyen and colleagues ${ }^{2}$ recently reported a series of 25 patients with BAV-I who received Perceval S prostheses. At 1-year follow-up, the overall survival was $88 \%$. Although a high incidence of pacemaker use was observed, no cases of severe paravalvular leaks, valve displacement, or structural deterioration were detected.

Typically, BAV-I is characterized by 3 asymmetric Valsalva sinuses and 2 cusps of different size: a smaller cusp (reference cusp) and a larger cusp (conjoint cusp) that is composed of 2 tiny cusps with a central raphe. The 2 cusps composing the conjoint cusp are retracted and less deep than the reference cusp (Figure 2, C). Irregular shape of the aortic annulus, asymmetric height of commissures, and unequal width of Valsalva sinuses may be responsible for insufficient stability of the sutureless bioprosthesis in BAV-I, its subsequent dislocation, and paravalvular leak. $^{3,4}$ In our case, the Perceval $\mathrm{S}$ bioprosthesis did not present any of the signs of structural deterioration that others have observed. ${ }^{5}$ The central intraprosthetic leak was apparently caused by inadequate leaflet coaptation because of the displacement of the valve.

\section{CONCLUSIONS}

Despite some reports of good results and interesting new proposed techniques ${ }^{1,3}$ in patients with BAV-I, the use of a Perceval S sutureless valve must be approached cautiously, because the risk of valve displacement and paravalvular leak is real. This experience should warn about the possible suboptimal long-term performance of the Perceval valve $S$ in BAV-I annuli.

\section{References}

1. Miceli A, Santarpino G, Pfeiffer S, Murzi M, Gilmanov D, Concistré G, et al. Minimally invasive aortic valve replacement with Perceval S sutureless valve: early outcomes and one-year survival from two European centers. J Thorac Cardiovasc Surg. 2014;148:2838-43.

2. Nguyen A, Fortin W, Mazine A, Bouchard D, Carrier M, El Hamamsy I et al. Feasibility and outcomes of sutureless aortic valve replacement in patients with bicuspid aortic valves. J Thorac Cardiovasc Surg. 2015;150: $851-7$.

3. Glauber M, Ferrarini M, Lio A, Miceli A. Dealing with a stenotic bicuspid aortic valve: is still an off-label procedure for a sutureless valve? J Thorac Cardiovasc Surg. 2015; 150:858-9.

4. Santarpino G, Pfeiffer S, Fischlein T. Sutureless valve implantation in a patient with bicuspid aortic valve. Int J Cardiol. 2012;157:e21-2.

5. Bouhout I, Noly PE, Parisi A, Bouchard D. First case of Perceval S prosthesis early structural valve deterioration: not an easy reoperation. J Thorac Cardiovasc Surg. 2016;152:e71-3. 